\title{
CULTURA-ESPETÁCULO NA MÍDIA: ESPACIALIDADE E PERSONAS DO CARNAVAL DA BAHIA NA IMPRENSA LOCAL
}

\author{
Lauro Almeida de Moraes ${ }^{1}$ \\ Cláudia Novaes Deina ${ }^{2}$
}

\section{Introdução}

O carnaval é uma das manifestações culturais mais conhecidas em todo o mundo e a festa popular mais celebrada no Brasil. Caracterizada como uma festividade plural e complexa, desenvolveu-se de forma peculiar em diferentes porções do território brasileiro, tornando-se elemento basilar da cultura nacional. Por todo o país, a folia carnavalesca reúne atores sociais antagônicos, produzindo um espaço de múltiplas leituras e significados.

Dentre os mais tradicionais do país, está o Carnaval de Salvador - denominado também, de forma imprecisa, mas simbólica do ponto de vista local, como Carnaval da Bahia $^{3}$ - que teve o período ampliado pelos gestores públicos locais a partir de 2017. Enquanto as festividades na maior parte do Brasil têm duração de seis dias, começando numa quinta-feira à noite e encerrando-se na manhã da quarta-feira de Cinzas, são doze dias de festa em Salvador.

Permeado pela aclamação popular e rico extrato simbólico-cultural, bem como por interesses governamentais e mercadológico-empresariais, este artigo tem por finalidade explorar as espacialidades e personas ${ }^{4}$ representadas com maior ênfase na imprensa baiana nos últimos anos. Para isso, toma como objeto de estudo fotografias

\footnotetext{
${ }^{1}$ Universidade Federal do Paraná (UFPR), Paraná, Brasil, e Universidade Estadual de Santa Cruz (UESC), Bahia, Brasil. E-mail: lauromoraes@ufpr.br. ORCID: http://orcid.org/0000-0003-0836-3941

${ }^{2}$ Universidade Federal do Paraná (UFPR), Paraná, Brasil, e Universidade Federal da Bahia (UFBA), Bahia, Brasil. Email: cnovaes19@gmail.com.ORCID: https://orcid.org/0000-0001-8370-2582

${ }^{3}$ Ao longo do artigo, adotar-se-á ambas as terminologias, com maior ênfase ao Carnaval da Bahia, tendo em vista a conotação simbólica em nível local. Ante a identificação e representatividade do Carnaval de Salvador em relação a todo o Estado, irradia-se um habitus carnavalesco, no sentido bourdieusiano (Bourdieu, 2001), com ampla influência no território baiano.

${ }^{4}$ Inspira-se nos sentidos atribuídos por Jung (2008) e Radcliffe-Brown (1973). Este é um dos termos adotados na sociologia e na antropologia cultural para "estudar a incorporação de padrões culturais à personalidade do indivíduo e as formas como os indivíduos passaram a agir de maneiras socialmente aprovadas em tarefas específicas" (Scott, 2010: 149). No carnaval, uma gama de personas desempenha funções particularmente esperadas nessa grande manifestação da vida em grupo. Trabalhadores, integrantes de grupos afros e afoxés, foliões pipoca ou de blocos e camarotes, turistas, celebridades, seja da política, da religião, da música, da televisão e das artes em geral, compõem esse espectro na Bahia.
} 
acerca do Carnaval da Bahia publicadas nas capas dos jornais de maior circulação local - A Tarde e Correio.

\section{Carnaval de Salvador: caracterização socioespacial}

O território ocupado pela folia carnavalesca na capital baiana abrange três regiões principais: Circuito Dodô, na região de Barra/Ondina, Circuito Osmar, no Campo Grande, e Circuito Batatinha, no Pelourinho (Figura 1). Para caracterizá-los, parte-se de uma compreensão socioespacial, assim grafado com intencionalidade tautológica - conforme também defende Catalão (2011) - a fim de reforçar o conteúdo social desses trajetos. Dessa forma, busca-se apreendê-los enquanto integrante da totalidade social, pois, como bem ressalta Santos (2006: 74), "é a totalidade que explica as partes".

Figura 1 - Circuitos do Carnaval de Salvador 2017

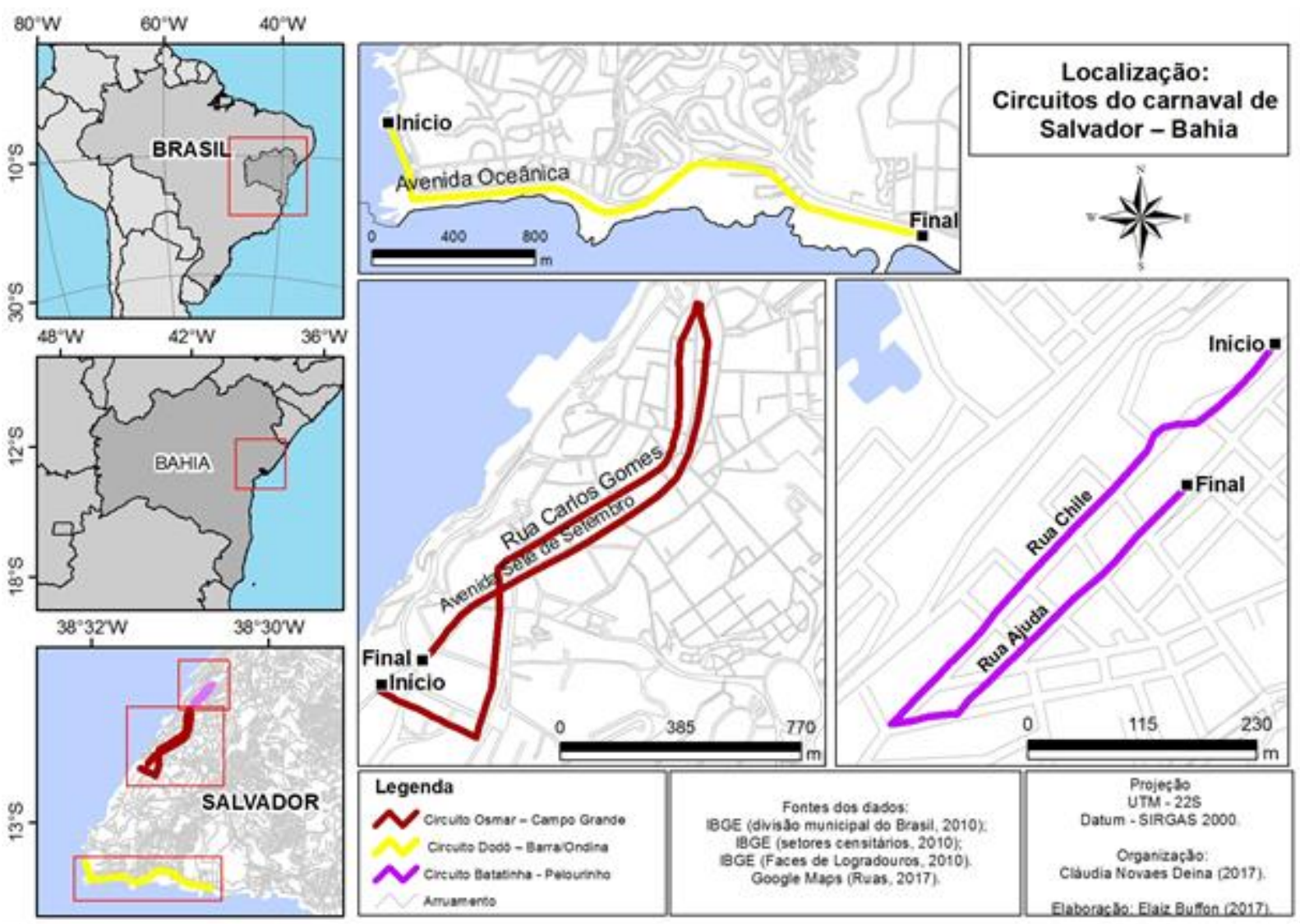

Fonte: IBGE e Google Maps, com intervenção dos autores.

O Circuito Batatinha está na região onde foram realizados os primeiros gritos carnavalescos de Salvador, ainda no século XVIII. A ideia é reviver carnavais passados 
e oferecer um ambiente mais familiar nas praças (Praça da Sé e Praça Castro Alves) e no famoso Pelourinho, localizado no chamado coração da cidade, caracterizado por uma mancha urbana de lazer e comércio ao ar livre, com variedade de teatros, museus, bares, igrejas, lojinhas e restaurantes.

Um dos diferenciais em relação aos Circuitos Dodô e Osmar é a ausência de trios elétricos. As principais atrações são marchinhas, fanfarras, concursos, desfiles e blocos, que percorrem as ruas estreitas do centro histórico. Também conhecido como Carnaval no Pelô, as atrações são gratuitas, com variedade de ritmos musicais, como samba-reggae, afoxé, MPB, pop e axé.

O mais tradicional circuito do Carnaval de Salvador, porém, é o Osmar, também chamado de Campo Grande, em alusão à região em que está situado o percurso de aproximadamente $4 \mathrm{~km}$ e 5 horas de duração. Estão neste trajeto a Avenida Sete, Praça Castro Alves e, por fim, a Rua Carlos Gomes, já no centro da cidade, onde ocorre a dispersão dos trios.

Assim como no Pelourinho, a paisagem também se caracteriza por casarões históricos, entre os quais passam os trios com artistas de renome. Além de ocuparem as avenidas e a Praça Castro Alves, os foliões, geralmente, também ocupam milhares de lugares em arquibancadas instaladas pela prefeitura, pagando valores entre $\mathrm{R} \$ 30$ e $\mathrm{R} \$ 60$.

$\mathrm{Na}$ orla marítima da cidade, o circuito Dodô/Barra Ondina é mais recente, com aproximadamente 4,5 km, ligando as praias da Barra e Ondina. A localização privilegiada inclui alguns dos hotéis mais luxuosos de Salvador, que também se tornam grandes camarotes durante o carnaval. Muitos outros são instalados ao longo do percurso, oferecendo shows privativos entre a passagem dos trios e blocos, buffet, acesso privado à praia e blocos uniformizados. $\mathrm{O}$ custo, por pessoa, para passar um dia de folia nesses locais, chega a $\mathrm{R} \$ 2$ mil.

A projeção de arrecadação, pela Prefeitura de Salvador, durante o período carnavalesco, nos últimos anos, ultrapassou a casa de $\mathrm{R} \$ 1$ bilhão. Segundo autores que pesquisaram o Carnaval da Bahia, a festividade leva às ruas da capital cerca de um milhão de pessoas, produzindo uma participação popular maior em relação a outros carnavais do Brasil (Miguez, 1996; Agier, 2000; Moura, 2001; Dias, 2002). Todavia, o contraste entre duas realidades culturais fica evidente: de um lado, o carnaval de luxo, usufruído por pessoas abastadas e/ou dispostas a dispender alta quantia pelos dias de folia VIP, particularmente turistas; do outro, o carnaval de rua, que congrega, sobretudo, foliões 
alijados dos camarotes e blocos pagos, em função dos custos envolvidos, além daqueles que optam, preferencialmente, por essa vertente da festa.

De forma simplificada, mas perfeitamente visível a um observador atento do carnaval em Salvador, há uma festa predominantemente branca e outra negra, com interseções entre ambas em alguns momentos. Nesse sentido, cabe ressaltar que a capital baiana é a cidade do mundo que possui a maior população negra fora do continente africano 5 , motivo pelo qual Agier (2000) comparou Salvador a uma "Roma Negra" em termos populacionais.

Dada essa composição demográfica, a cultura africana permeia o Carnaval da Bahia desde a sua origem (Rodrigues, [1932] 1988; Sodré, 1988). Entretanto, a institucionalização da africanidade na folia carnavalesca, em Salvador, ocorreu a partir da criação dos blocos de afoxé e a consolidação veio com a instituição dos blocos afros na década de 1970, especialmente do Ilê Aiyê. Esses blocos surgiram dentro dos terreiros de candomblé espalhados pela cidade, onde a maioria dos habitantes são negros, como o bairro da Liberdade.

Os elementos territoriais e socioculturais supramencionados emaranham-se durante o carnaval, evidenciando espacialidades e personas, que são reiteradas a partir da ritualização e da "restauração do comportamento", como denominado na antropologia da performance (Turner, 1974; Schechner, 1995; Silva, 2005) ${ }^{6}$, e ganham visibilidade e nova organização sócio-simbólica por meio da midiatização (Fausto Neto, 2008; Braga, 2012; Hjarvard, 2013). Com efeito, o carnaval de Salvador também se consolidou como uma festa com grande apelo e suporte tecno-discursivo midiático, o que vem ao encontro do objetivo desse estudo: identificar espacialidades e personas representadas com maior frequência e ênfase na imprensa local nos últimos anos.

\section{Carnaval e cultura-espetáculo na sociedade midiatizada}

\footnotetext{
${ }^{5}$ Segundo estimativas do Instituto Brasileiro de Geografia e Estatística (IBGE), em 2015, Salvador possuía 2.921.087 habitantes, sendo que 80,9\% declararam-se como negros ou pardos no último censo.

${ }^{6} \mathrm{O}$ rito teatraliza, dramatiza e legitima comportamentos sociais, conforme Turner (1974). Ao mesmo tempo, interrompe a vida rotineira e as tradicionais representações de mundo. Além de gerar práticas diversas e distintivas, torna-se um princípio unificador de práticas sociais, como se observa no repertório de papéis sociais e de padrões de comportamento adotados pelos foliões no carnaval. $\mathrm{O}$ "comportamento restaurado" (restauração de eventos performáticos) possibilita, por sua vez, o resgate de práticas e atividades culturais, posto que as "as performances são atividades culturais criativamente reproduzidas ao longo do tempo, num processo que tende a envolver interesses diversos e sugerir pluralidade de significados" (Silva 2005: 57).
} 
A lógica publicitária consolidou-se como instrumento conveniente e eficaz ao sistema produtivo contemporâneo. Todavia, análises recentes apontam para um novo fenômeno sociocomunicacional, calcado na sinergia da informação com o setor do entretenimento. Essa nova orientação do tecnocapitalismo global teria originado o que Kellner (2003b) designa de infotainment society. Tal perspectiva suplanta as noções de sociedade do conhecimento, da informação e pós-industrial, orientando a dinâmica da sociedade, da cultura e da vida cotidiana neste início de novo milênio. Nesse aspecto, Thussu (2007) enfatiza a penetração do infoentretenimento no âmbito do jornalismo, sobretudo por meio da televisão. E da TV, este também migra para a mídia impressa, foco deste artigo.

Com efeito, os processos de midiatização, assentados no infoentretenimento, favorecem a amplificação de "espaços de consumo", cuja ideia trata da mercantilização do espaço público, transformado em variados experience markets, na expressão de Carmona (2010). Estes, segundo o autor, permitem excluir segmentos mais pobres da sociedade por meio do poder econômico. Uma exclusão patente no carnaval de rua de Salvador, em que ocorre clara sinergia entre mercantilização do espaço público, visibilidade midiática e espetacularização da cultura.

Tal noção alinha-se à concepção de "fetichismo da paisagem-mercadoria", que evidencia o gosto imagético da imprensa, espectadores e leitores. Muitas reportagens transformam, então, a paisagem e a cultura originais em "cenários artificiais onde se desenrolam espetáculos devidamente ensaiados para cativar o turista" (Carvalho, 2007: 294). Na definição de Carlos (2011), ensejar-se-ia um "mundo mercadoria", ancorado no que Lefebvre ([1972] 2008) denominou de valor de troca.

Segundo Dias (2002: 10), os espetáculos públicos passaram a ter primazia no planejamento governamental, os quais foram metamorfoseados como "forças econômicas e simbólicas de uma conjuntura denominada pós-moderna". Sob esse viés, grande parte do Carnaval da Bahia estruturar-se-ia como um produto da indústria cultural, com forte apelo mercadológico, enquanto megaevento e atrativo turístico, o que também comporta uma intensa exploração da imagem e culto a celebridades - tendência que Morin (1997) identificara em sua obra pioneira sobre a cultura de massa.

Ao explorar a imagem espetacular do turismo, o jornalismo, por sua vez, almeja atrair a audiência. Desta forma, "a mídia busca encantar ao leitor/espectador/internauta, assim como o turismo ao turista, conduzindo-os à diversão, ao prazer" (Moraes \& 
Gândara, 2016: 14). Essa lógica insere-se numa relação social, em que a recepção do espetáculo integra a vida cotidiana, e esta relação é mediada por imagens (Debord, 1997), dando ensejo ao que Kellner (2003a) denomina como “cultura do espetáculo". Acentuase, portanto, o caráter público e imanente às sociedades humanas das manifestações espetaculares, potencializadas por "gigantescas máquinas midiáticas de espetacularização" (Rubim, 2005: 18) - os meios de comunicação, que catalisam todas as formas de espetáculo na contemporaneidade.

Como ressalta Kellner (2003a: 11), “o espetáculo da mídia está invadindo todos os campos da experiência, desde a economia e a cultura até a vida cotidiana [...]”. E é pertinente reconhecer o papel da imprensa e da mídia, como um todo, nesse processo e em sua dinâmica de espacialização. A midiatização da sociedade, em conjunto com as novas tecnologias da comunicação e informação, desencadeia uma reorganização das relações socioespaciais, expandindo a presença espacial do complexo cultural a níveis jamais experimentados (Ferraz, 2007).

Nessa nova ordem espacial, os referenciais imagéticos e o processo comunicativo suplantam o espaço físico. Sendo assim, emergem ambiguidades espaciais a partir das representações comunicacionais. A constituição de redes e fluxos de informação espacialmente dispersos, interconectando pessoas e lugares, abre, portanto, perspectivas para que as teorias da produção espacial sejam alinhadas às teorias da comunicação/mediação (Jansson, 2005). Isso implica, então, compreender como a comunicação produz espaços e como os espaços produzem comunicação.

\section{Carnavalizando a pesquisa: procedimentos metodológicos}

Desenvolveu-se uma abordagem metodológica sustentada na pesquisa documental, na Análise de Conteúdo e na técnica de emparelhamento, o que exigiu, preliminarmente, uma revisão bibliográfica que contemplasse a interface entre geografia, antropologia e midiatização.

No âmbito da pesquisa documental, foram coletadas imagens publicadas nas capas dos jornais de maior circulação local - A Tarde e Correio - no período que compreende 2014 a 2017. Porém, em se tratando de um estudo com caráter exploratório, foram selecionadas, como amostra, imagens de um único período de carnaval, tomando-se como objeto de estudo fotografias acerca do Carnaval da Bahia em 2016. Tal recorte conveio 
tanto para uniformização da análise quanto para síntese de apresentação dos resultados, pois ilustraram, de modo geral, as espacialidades e personas representadas com maior frequência e ênfase na imprensa local nos últimos anos, cuja identificação é o objetivo da pesquisa.

Para interpretação dos dados, recorreu-se à Análise de Conteúdo, extraindo-se as "comunicações" perceptíveis a partir das fotografias publicadas pelos jornais, "segundo a frequência de presença (ou de ausência) de itens de sentido" (Bardin, 1977: 37). O viés analítico, por sua vez, fundamentou-se, em especial, na sociologia da imagem, de Martins (2016), na antropologia da performance, de Turner (1974) e Schechner (1995), e na perspectiva da geografia da comunicação, de Jansson (2005), que preconiza o alinhamento entre teorias da produção espacial e da comunicação/mediação. Nesse aspecto, as análises e resultados foram validados por meio da técnica de emparelhamento, que permitiu associar os dados recolhidos aos modelos e pressupostos teóricos levantados, com a finalidade de compará-los (Laville \& Dionne, 1999), bem como a partir da experiência existencial dos autores, por meio de vivências e observações nãosistemáticas do carnaval e da imprensa baiana.

Conforme exorta Bourdieu (2007: 466), essa ousadia epistemológica é necessária e útil à ciência, a fim de "transgredir a regra não escrita que deseja que apenas possam intervir na construção científica os dados coletados em condições socialmente definidas como científicas, isto é, pela entrevista ou observação armada". Desse modo, dados mensuráveis - primários e secundários - foram confrontados e complementados com o cabedal de informações e experiências acumulado acerca do carnaval de Salvador e do jornalismo baiano, com intuito de conferir substância e pertinência à análise socioespacial das imagens selecionadas.

\section{Carnaval da Bahia na imprensa local: análises e resultados}

De modo geral, percebeu-se um tratamento difuso do Carnaval da Bahia pelos principais jornais locais. Ao mesmo tempo em que se nota proeminente culto a celebridades da música baiana nas capas dos jornais locais, ocorre certa valorização do patrimônio simbólico associado à essa festividade no território baiano. Desvela-se ainda uma tendência de resgate dos antigos carnavais, com ênfase em fotografias que chamam a atenção para o carnaval de rua, especialmente com participação do folião pipoca, como 
são denominados aqueles que não integram blocos nem camarotes. Claramente, um afã para ratificar a maciça apropriação do espaço público proporcionada pela festa.

Notadamente, todos esses elementos compõem o apelo midiático do carnaval baiano, cujo suporte tecno-discursivo também se tornou fundamental para que ganhasse visibilidade e destaque na imprensa. A bem da verdade, parafraseando Turner (1974), todo o ritual carnavalesco, que envolve performances diversas durante a passagem de blocos, trios e afoxés, exerce fascínio. Está no imaginário popular como expressão de liberdade e alegria, bem como tem seu potencial reforçado e até ampliado por "gigantescas máquinas midiáticas de espetacularização" (Rubim, 2005: 18).

Com efeito, a observação criteriosa das capas de $A$ Tarde e Correio ratifica que as espacialidades do carnaval passam por uma reorganização sócio-simbólica a partir da midiatização (Fausto Neto, 2008; Braga, 2012; Hjarvard, 2013). O espaço vivido da folia nas avenidas e ruas de Salvador transfigura-se em um espetáculo para ser visto e consumido (Debord, 1977; Carmona, 2010), propagado e vendido como infoentretenimento nas páginas dos jornais (Kellner, 2003a, 2003b; Thussu, 2007). Isso implica considerar um movimento sinérgico em que tanto a mídia induz espacialidades da folia quanto os espaços produzem comunicação a partir do carnaval (Jansson, 2005).

$\mathrm{O}$ viés espetacular e de infoentretenimento fica particularmente evidenciado pela marcante propagação de celebridades da música baiana pela imprensa local. Personalidades como Ivete Sangalo, Cláudia Leite, Bell Marques, Carlinhos Brown, Saulo Fernandes e Daniela Mercury, entre outras, foram destaque nas capas de A Tarde e Correio no período sob análise. Pode-se relacionar esse culto à imagem de astros da cultura mainstream tanto à fetichização de vedetes da imprensa, aludida por Morin (1997), quanto à crítica de Martins (2016: 23) de que "a fotografia é uma das grandes expressões da desumanização do homem contemporâneo, sobretudo porque permitiu a separação cotidiana da pessoa em relação a imagem".

Notou-se, inclusive, similaridade na abordagem imagética dos jornais, como nas Figuras 2 e 3 - representações do mesmo dia de carnaval. Corrobora-se, então, com o entendimento de que tanto cenários quanto as representações midiáticas são planejados e orientados para o encantamento de turistas, leitores, espectadores, internautas, conduzindo-os à diversão, ao prazer, ainda que remotamente (Carvalho, 2007; Moraes \& Gândara, 2016). 
Figura 2 - Samba e Axé marcam a cadência da folia

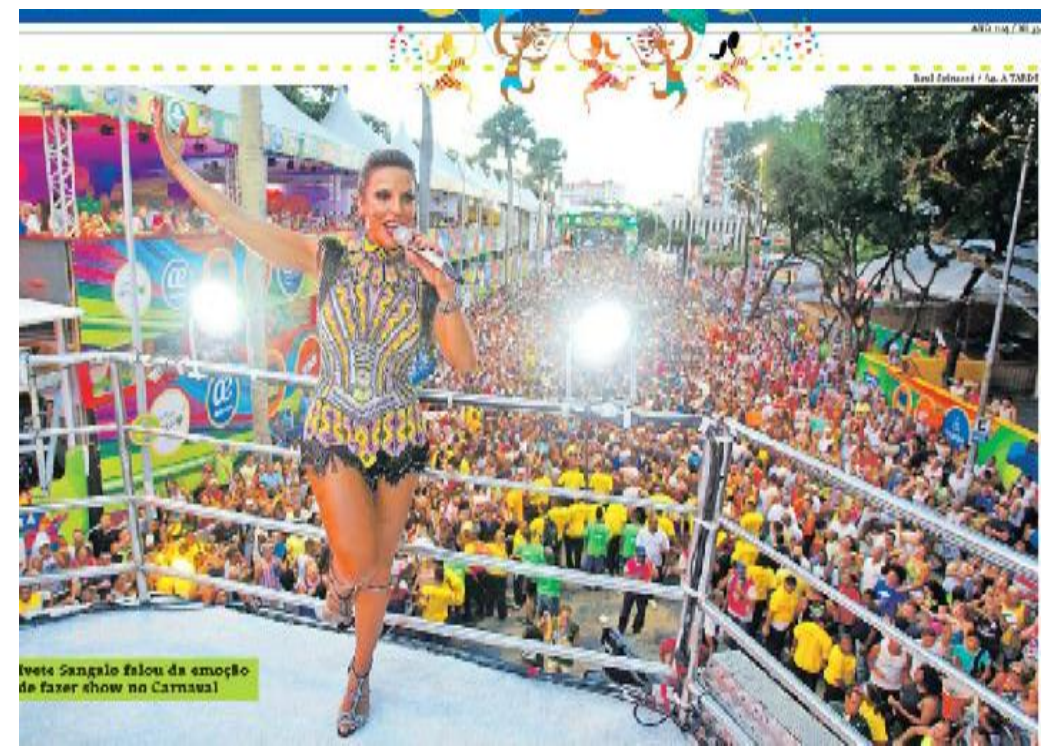

Fonte: A Tarde, 05 de fevereiro de 2016.

Figura 3 - Superpipoca da Ivete

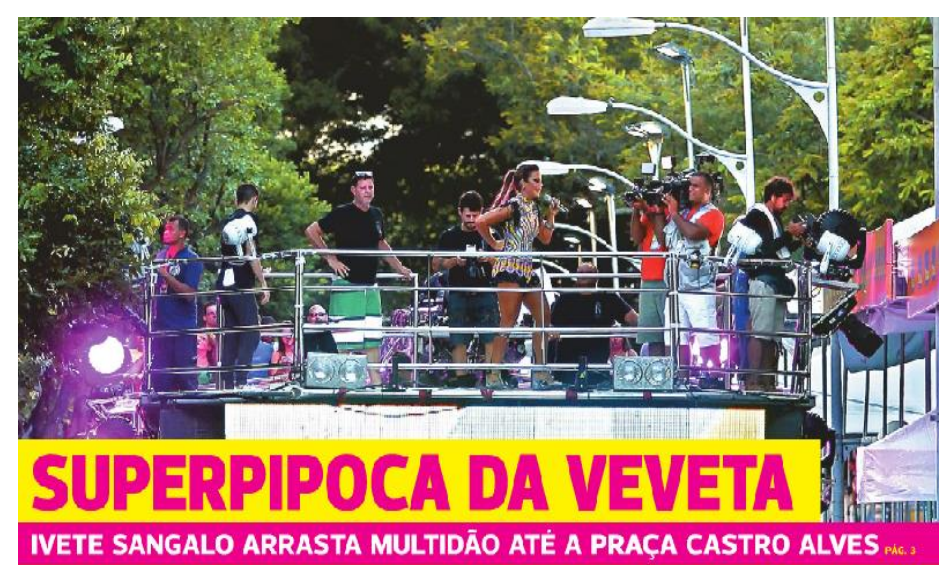

HOJE TEM FURDUNÇO NA AVENIDA E SAULO SEM CORDAS NA BARRA

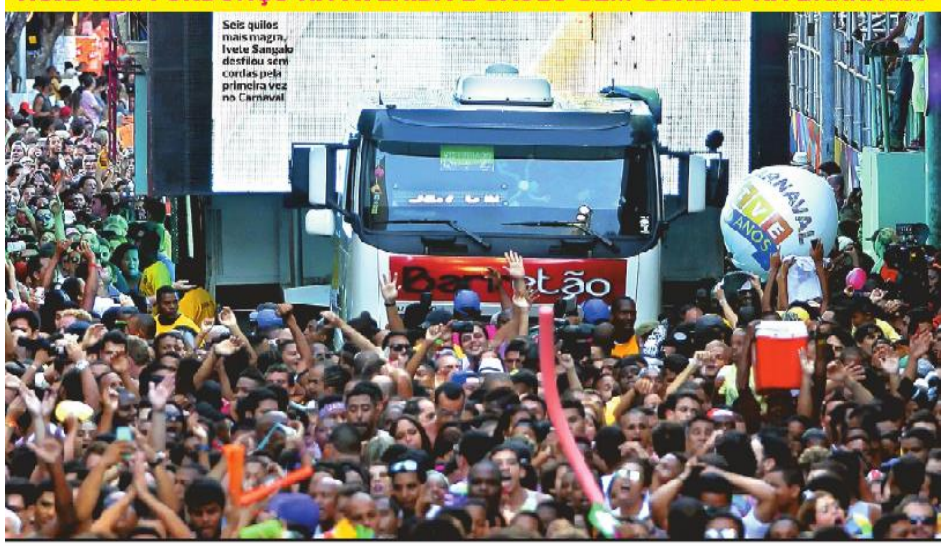

Fonte: Correio, 05 de fevereiro de 2016. 
Em ambos os órgãos de imprensa, a cantora Ivete Sangalo aparece no trio elétrico, cercado por uma multidão de foliões pipoca no Circuito Osmar, no Campo Grande. Esse processo de midiatização demonstra a repercussão do carnaval no cotidiano do lugar e quão importante é esse fenômeno para a cultura local (Ferraz, 2007). Todavia, com certa naturalidade jornalística, também escapa o movimento paradoxal da festividade nas páginas dos jornais, ao destacar-se o fato da artista ter se apresentado pela primeira vez "sem cordas" - expressão que revela um outro lado da festa, em que cordões de isolamento separam os foliões que pagam para fazer parte de blocos dos demais. Esses cordões foram ignorados, senão suprimidos, nas imagens de capa que representaram o Carnaval da Bahia. Contudo, acompanham os trios de artistas de renome, especialmente ao longo do Circuito Dodô, em Barrra/Ondina, estabelecendo tanto barreiras físicas quanto simbólicas no espaço público. O carnaval de rua de Salvador contrasta, nitidamente, com o que se pode chamar de carnaval de mercado (Miguez, 1996; Dias, 2002).

Com efeito, ante a magnitude do carnaval baiano, tem ocorrido um avassalador processo de mercantilização, o que tende a suprimir elementos que foram imprescindíveis para a produção da festa, enquanto manifestação da cultura popular. Esse fato repercute no que Lefebvre ([1972] 2008) discute em relação ao valor de uso, como apropriação necessária a realização da vida cotidiana, e valor de troca, enquanto mercadoria. Nessa lógica, a espacialidade do Carnaval da Bahia revela a constituição de um "mundo mercadoria", conforme pontua Carlos (2011: 77). Percebeu-se, de fato, que a imprensa local dá grande visibilidade para artistas e empresários, favorecendo a atribuição da cultura como produto, o qual se materializa no espaço de vivência da festividade.

Nos últimos anos, houve notória valorização dos camarotes privados, os quais possuem ampla infraestrutura, serviços e múltiplas atrações artísticas, promovendo, desse modo, a "festa" dentro da festa. Essa dimensão, em que o espaço da festividade é transformado em mercadoria de luxo para quem pode pagar, também ficou submersa no infoentretenimento das capas dos jornais locais. Enquanto instrumentos e componentes do tecnocapitalismo, bem como catalisadores da imagem espetacular do carnaval e do turismo, depreende-se que não há interesse nem seria de bom tom enfatizar uma seletividade socioespacial, econômica e, consequentemente, étnica, tendo em vista a estratificação social baiana e sua arraigada inter-relação com o carnaval (Carneiro, 1986; Sodré, 1988, Rodrigues, 1988; Agier, 2000; Moura, 2001). 
Esse processo de mercantilização estaria colocando em risco a magnitude da expressividade popular do carnaval baiano? Conjectura-se que seria um dos motivos pelos quais blocos "sem cordas", que saem nas ruas de Salvador, estejam perdendo concentração de público e, por outro lado, a quantidade de pessoas que procuram os camarotes é cada vez maior (Dias, 2002). Cabe, no entanto, a seguinte indagação: o carnaval dos camarotes resistiria diante do declínio do carnaval de rua?

Notadamente, nesses tensionamentos, a vida cotidiana surge como nível da apropriação e do conflito, em que as diferenças são concretizadas. Por isso, como forma de revalorizar o carnaval de rua, o poder público local tem contratado cantores consagrados para puxar trios elétricos "sem corda" no carnaval de Salvador, como também enfatiza a Figura 4. O objetivo é atrair o povo para as ruas, como nos primórdios carnavais, tendo em vista que a historicidade da festa perpassa pela valorização da rua enquanto espaço público de diversão popular. E foi desse modo que o Carnaval da Bahia se transformou numa das maiores celebrações populares do mundo. Conforme Rodrigues ([1932] 1988), desde o início do século XX, os negros e mestiços levavam para as ruas seus emblemas, batuques e coreografias horrorizando as elites baianas. Contudo, apesar dos processos de repressão, a africanização do carnaval de Salvador ganhou força ao longo do século XX e contribuiu de forma decisiva para a apoteose da festa.

Figura 4 - Triunfo da pipoca

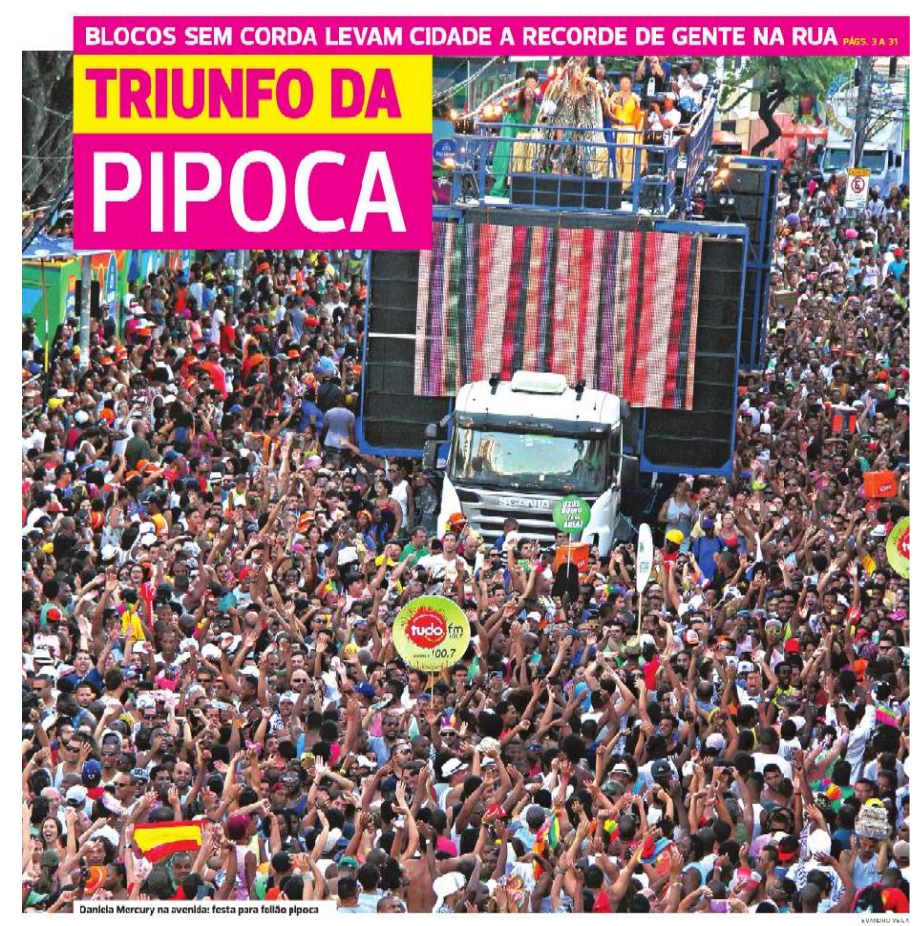

Fonte: Correio, 10 de fevereiro de 2016. 
Com efeito, as capas dos principais jornais locais também têm dado bastante ênfase ao carnaval de rua baiano, como se observou no estudo em questão. Na Figura 4, o Correio ressalta "o triunfo da pipoca" diante da multidão que acompanhou a cantora Daniela Mercury num trio "sem cordas". Nesse sentido, Martins (2016) dispõe que a fotografia vai além de um instrumento de mera ilustração ou confirmação. Ainda que seja um crítico da supervalorização das imagens na contemporaneidade, reconhece que abarcam o cotidiano e possibilitam o conhecimento da sociedade.

Ela é constitutiva da realidade contemporânea e, nesse sentido, é, de certo modo, objeto e também sujeito. São amplas e numerosas as situações em que a imagem fotográfica e suas variantes, no filme e no vídeo, antecipam ou mesmo substituem a própria pessoa na reprodução das relações sociais e até na inovação imaginária (Martins, 2016: 23).

Nesse sentido, a partir das figuras 5 e 6, apreende-se a inter-relação entre o sincretismo religioso e a maioria das festas populares da Bahia, particularmente o carnaval (Sodré, 1988, Rodrigues, 1988). Assim, no dia 02 de fevereiro, os baianos fazem festa para Iemanjá, Orixá feminino cultuado no Candomblé e na Umbanda, que tem sua origem na ancestralidade africana, pois era cultuada pelos Iorubás ${ }^{7}$.

Figura 5 - Aguas de Iemanjá

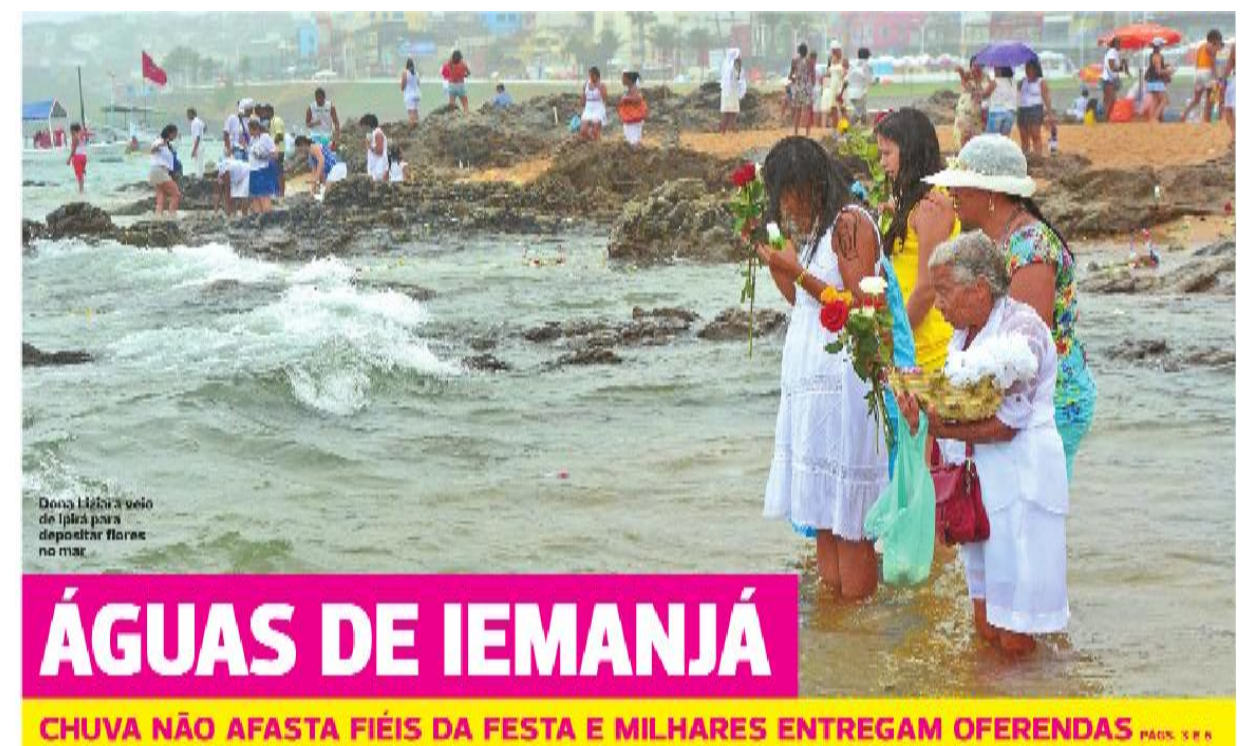

Fonte: Correio, 03 de fevereiro de 2016.

Figura 6 - Presentes para Iemanjá.

\footnotetext{
${ }^{7}$ Um dos maiores grupos étnico-linguísticos da África Ocidental, predominantemente no sudoeste da Nigéria, no Benim e no Togo. Nas últimas décadas do tráfico negreiro, entre o fim do século XVIII e o fim do XIX, um grande contingente de escravos dessa região foi trazido para Salvador, contribuindo para a marcante presença da cultura yourubá-nagô na Bahia (Carneiro, 1986).
} 


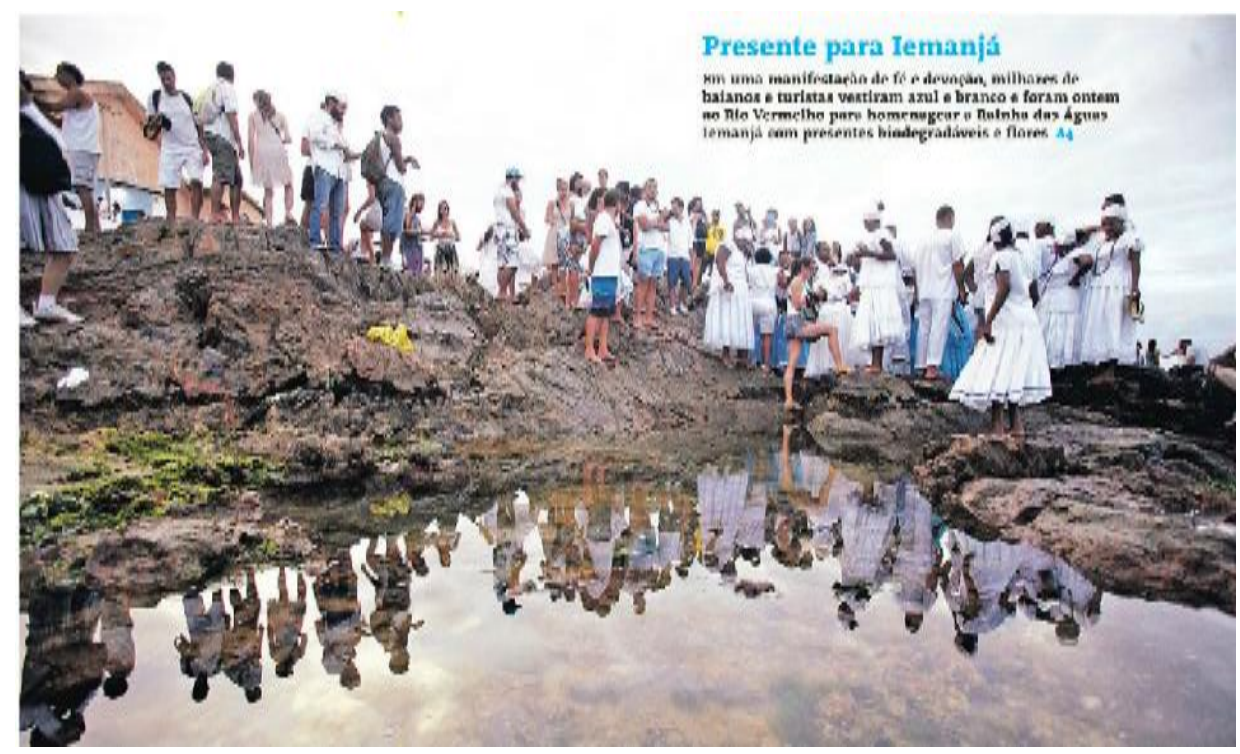

Fonte: A Tarde, 03 de fevereiro de 2016.

As pessoas - entre as quais muitas baianas do Candomblé - usam trajes predominantemente brancos. Oferecem presentes para Iemanjá nas águas da praia do Rio Vermelho, em Salvador, local onde fica o templo de Iemanjá. A fé é tanta que, apesar da chuva naquele ano - como ressalta a capa do Correio (Figura 5) - devotos compareceram para homenagear o Orixá e pedir suas bênçãos e proteção para todo o ano. Esses milhares de fiéis creem e sentem-se protegidos pela divindade considerada a Rainha do Mar e Mãe de todos os Orixás.

Tal comportamento restaurado, na expressão de Schechner (1995), em que esse evento performático é resgatado e reproduzido a cada ano, figura como um traço distintivo das atividades culturais do Carnaval da Bahia, quando este ocorre no início do mês de fevereiro. Desse modo, tais imagens tornam-se marcantes na semana do carnaval, evidenciando a forte ligação da celebração da divindade com as festividades carnavalescas. Nota-se, portanto, que a festa de Iemanjá foi publicada, com destaque de capa, pelos dois principais jornais impressos da Bahia. Essas fotografias representam o cotidiano da cidade, que está presente no carnaval por meio do patrimônio simbólico dos povos de origem africana (Miguez, 1996; Agier, 2000; Moura, 2001; Dias, 2002). Referências culturais que se consubstanciam em outras manifestações de restauração do comportamento, principalmente nos desfiles dos blocos afros e afoxés.

\section{Considerações finais}


A partir da análise das fotografias nas capas do jornal A Tarde e Correio, entre as personas, destacaram-se celebridades, notoriamente tomadas pela imprensa como vedetes, que magnetizam e alimentam o imaginário popular. Consequentemente, tornamse atrativos primordiais para vendagem de jornais. Dessa forma, compõem também a espacialidade construída e evidenciada, com prevalência do carnaval de rua e fragmentos da cultura africana permeando o universo da festividade.

A cultura do espetáculo foi decisiva para que o carnaval de Salvador se transformasse num dos maiores espetáculos do mundo. Com efeito, ao lado do glamour das celebridades e do carnaval de luxo, as imagens analisadas também colocam em evidência a grande participação popular que ocorre no Carnaval da Bahia, por meio da multidão de foliões que acompanha trios elétricos pelas ruas de Salvador. Afinal, a plateia é parte fundamental dessa festa, assim como de grande parte dos eventos performáticos e espetaculares.

Ademais, notou-se ainda destaque ao sincretismo religioso, que permeia a cultura baiana, a partir das imagens sobre a festa de Iemanjá, que ocorreu concomitante ao carnaval em 2016. Então, mesmo que este seja o foco principal, as capas dos jornais de maior circulação local incluíram na pauta outra festividade, relacionada à espiritualidade de origem africana, em face do seu sentido e significado no cotidiano do povo baiano. Uma demonstração cabal da confluência carnavalesca entre sagrado e profano, assim como entre restauração do comportamento e midiatização. Nitidamente, o resgate e reprodução de práticas e atividades culturais são alvos de interesse da imprensa. A cobertura, em geral, não prescinde de elementos icônicos, como foi a festa de Iemanjá naquele ano ou como ocorre em todo carnaval com os Filhos de Gandhy, o maior e mais famoso afoxé da Bahia.

Diante das mediações e conflitos que ocorrem no cotidiano do lugar para produção do espaço do Carnaval da Bahia, o qual repercute para além do lapso temporal da festividade, esse fenômeno merece atenção. Particularmente no que tange aos processos de midiatização, cabe ressaltar a multiplicidade da produção e reprodução representacional, que é permeada por critérios editoriais e pessoais, bem como por interesses governamentais e mercadológico-empresariais, e, igualmente, carecem de aprofundamento em novos estudos. Em um movimento controverso e dialético, o furor dos tensionamentos emerge mesmo em meio ao êxtase da folia. 


\section{Referências bibliográficas}

AGIER, Michel. Anthropologie du Carnaval: La Ville, la Fête et l'Afrique à Bahia. Marseille: Parenthèses/IRD, 2000.

BARDIN, Laurence. Análise de conteúdo. Lisboa: Edições 70, 1977.

BOURDIEU, Pierre. Meditações Pascalianas. Rio de Janeiro: Bertrand Brasil, 2001.

BOURDIEU, Pierre. A Distinção: crítica social do julgamento. São Paulo: Edusp; Porto Alegre: Zouk, 2007.

BRAGA, José L. Circuitos versus campos sociais. In: MATTOS, Maria A.; JANOTTI JUNIOR, Jeder; JACKS, Nilda. (Orgs). Mediação \& midiatização. Salvador: EDUFBA, 2012: 29-52.

CARLOS, Ana F. A condição espacial. São Paulo: Contexto, 2011.

CARMONA, Mitchell. Contemporary Public Space: Critique and Classification, Part One: Critique. Journal of Urban Design, v. 15, n. 1, p. 123-148, 2010.

CARNEIRO, Edson. Candomblés da Bahia. Rio de Janeiro: Civilização Brasileira, 1986.

CARVALHO, André L. P.. O turismo como produto da indústria cultural nas enunciações da mídia. In: PAIVA, Cláudio C.; BARRETO, Emília B.; BARRETO, Virgínia S. (Orgs.). Mídia \& Culturalidades: análises de produtos, fazeres e interações. João Pessoa: Universitária, 2007: 277-297.

CATALÃO, Igor. Socioespacial ou sócio-espacial: continuando o debate. Revista Formação Online, v. 2, n. 18, p. 39-62, jul./dez. 2011.

DEBORD, Guy. A sociedade do espetáculo. Rio de Janeiro: Contraponto, 1997.

DIAS, Clímaco C. S. Carnaval de Salvador: mercantilização e produção de espaços de segregação, exclusão e conflito. Dissertação (Mestrado em Geografia) - Instituto de Geociências, Universidade Federal da Bahia, Salvador, 2002.

FAUSTO NETO, Antônio. Fragmentos de uma analítica da midiatização. Matrizes, v. 1, n. 2, p. 89-105, abr. 2008.

FERRAZ, Cláudio B. O estudo geográfico dos elementos culturais - considerações para além da Geografia Cultural. Terra Livre, v. 2, n. 29, p. 29-50, 2007.

HJARVARD, Stig. The mediatization of culture and society. London: Routledge, 2013.

JANSSON, André. For a geography of communication. In: ACSIS NATIONELLA FORSKARKONFERENS FÖR KULTURSTUDIER, 2005, Norrköping. Anais... Linköping: Linköping University, 2005: 1-16. Disponível em: <www.ep.liu.se/ecp/015/040/ecp015040b.pdf>. Acesso em: 12/02/2017.

JUNG, Carl. O eи e o inconsciente. 21. ed. Petrópolis: Vozes, 2008. 
KELLNER, Douglas. A cultura da mídia e o triunfo do espetáculo. Líbero, São Paulo, v. 6 , n. 11, p. 4-15, jun. 2003a.

KELLNER, Douglas. Media Spectacle. London: Routledge, 2003b.

LAVILLE, Christian; DIONNE, Jean. A construção do saber: manual de metodologia da pesquisa em ciências humanas. Belo Horizonte: UFMG, 1999.

LEFEBVRE, Henry. Espaço e política. Belo Horizonte: Editora UFMG, [1972] 2008.

MARTINS, José de S. Sociologia da fotografia e da imagem. 2. ed. São Paulo: Contexto, 2016.

MIGUEZ, Paulo C. Carnaval Baiano: as tramas da alegria e as teias de negócios. Dissertação (Mestrado em Administração), Escola de Administração, Universidade Federal da Bahia, Salvador, 1996.

MORAES, Lauro A.; GÂNDARA, José M. G. Midiatização e espetacularização do turismo. Turismo \& Sociedade, v. 9, n. 1, p. 1-18, 2016.

MORIN, Edgard. Cultura de massa no século XX: o espírito do tempo. 9 ed. Rio de Janeiro: Forense Universitária, 1997. (Volume I - Neurose)

MOURA, Milton. Carnaval e Baianidade: Arestas e curvas na coreografia de textos identitários do carnaval de Salvador. Tese (Doutorado em Comunicação), FACOM, Universidade Federal da Bahia, Salvador, 2001.

RADCLIFFE-BROWN, Alfred R. Estrutura e função na sociedade primitiva. Petrópolis: Vozes, 1973.

RODRIGUES, Raymundo N. Os Africanos no Brasil. 7. ed. São Paulo: Nacional; Brasília: UnB, [1932] 1988.

RUBIM, Antônio A. C. Espetáculo. In: RUBIM, Antônio A. C. Cultura $e$ atualidade. Salvador: EDUFBA, 2005: 11-28.

SANTOS, Milton. A natureza do espaço: técnica e tempo, razão e emoção. 4. ed. São Paulo: Edusp, 2006.

SCHECHNER, Richard. Restauração do comportamento. In: BARBA, Eugênio \& SAVARESE, Nicola. A arte secreta do ator: dicionário de antropologia teatral. Campinas: Hucitec, 1995: 205-210.

SCOTT, John (Org.). Sociologia: conceitos-chave. Rio de Janeiro: Zahar, 2010.

SILVA, Rubens Alves. Entre "artes" e "ciências": a noção de performance e drama no campo das ciências sociais. Horizontes Antropológicos, v. 11, n. 24, 2005: 35-65.

SODRÉ, Muniz. O terreiro e a cidade: a forma social negro-brasileira. Petrópolis: Vozes, 1988. 
THUSSU, Daya K. News as entertainment: the rise of global infotainment. London: Sage, 2007.

TURNER, Victor. O processo ritual. Petrópolis: Vozes, 1974.

Data de submissão: 14 de setembro de 2019

Data de publicação: 20 de dezembro de 2021 